\title{
NMDA receptor subunits have different roles in NMDA-induced neurotoxicity in the retina
}

\author{
Ning Bai ${ }^{1,4^{*}}$, Tomomi Aida ${ }^{1}$, Michiko Yanagisawa' ${ }^{1}$ Sayaka Katou${ }^{1}$, Kenji Sakimura ${ }^{5}$, Masayoshi Mishina ${ }^{6}$
} and Kohichi Tanaka ${ }^{1,2,3^{*}}$

\begin{abstract}
Background: Loss of retinal ganglion cells (RGCs) is a hallmark of various retinal diseases including glaucoma, retinal ischemia, and diabetic retinopathy. N-methyl-D-aspartate (NMDA)-type glutamate receptor (NMDAR)-mediated excitotoxicity is thought to be an important contributor to RGC death in these diseases. Native NMDARs are heterotetramers that consist of GluN1 and GluN2 subunits, and GluN2 subunits (GluN2A-D) are major determinants of the pharmacological and biophysical properties of NMDARs. All NMDAR subunits are expressed in RGCS in the retina. However, the relative contribution of the different GluN2 subunits to RGC death by excitotoxicity remains unclear.

Results: GluN2B- and GluN2D-deficiency protected RGCs from NMDA-induced excitotoxic retinal cell death. Pharmacological inhibition of the GluN2B subunit attenuated RGC loss in glutamate aspartate transporter deficient mice.

Conclusions: Our data suggest that GluN2B- and GluN2D-containing NMDARs play a critical role in NMDAinduced excitotoxic retinal cell death and RGC degeneration in glutamate aspartate transporter deficient mice. Inhibition of GluN2B and GluN2D activity is a potential therapeutic strategy for the treatment of several retinal diseases.
\end{abstract}

Keywords: NMDA receptor, GluN2B, GluN2D, Excitotoxicity, Retina, Glaucoma, Glutamate transporter

\section{Background}

Glutamate is the major excitatory neurotransmitter in the mammalian central nervous system. However, its accumulation in extracellular spaces kills neurons through excitotoxic mechanisms via activation of glutamate receptors [1]. Excitotoxic neuronal cell death is thought to be a final common pathway in various neurological diseases, ranging from acute ischemic stroke to chronic neurodegenerative diseases such as Alzheimer's disease and amyotrophic lateral sclerosis [2-5]. Glutamate excitotoxicity has also been proposed to be an important contributor to the death of retinal ganglion cells (RGCs) in glaucoma and ischemia-related conditions such as vessel occlusion and

\footnotetext{
* Correspondence: bai.ning.aud@mri.tmd.ac.jp; tanaka.aud@mri.tmd.ac.jp 'Laboratory of Molecular Neuroscience, Medical Research Institute, Tokyo Medical and Dental University, 1-5-45 Yushima, Bunkyo-ku, Tokyo 113-8510, Japan

${ }^{2}$ The Center for Brain Integration Research, Tokyo Medical and Dental University, Tokyo, Japan

Full list of author information is available at the end of the article
}

diabetic retinopathy [6-8], although some investigations have failed to confirm elevated glutamate concentration both in human patients with glaucoma [9] and in animal models of glaucoma $[10,11]$. The toxic effects of glutamate on RGCs are predominantly mediated by the overstimulation of N-methyl-D-aspartate (NMDA)-type glutamate receptors (NMDARs) due to their extreme permeability to calcium ions [12].

NMDARs are composed of various combinations of GluN1 and GluN2 (GluN2A-GluN2D) subunits and, in some cases, GluN3 (GluN3A and GluN3B) subunits. GluN2 subunits are major determinants of the functional properties of NMDARs, including characteristics such as agonist affinity, deactivation kinetics, single-channel conductance, $\mathrm{Ca}^{2+}$ permeability, and sensitivity to $\mathrm{Mg}^{2+}[13]$. However, the relative contribution of different GluN2 subunits to RGC death by excitotoxicity remains unclear.

We previously reported that NMDAR-mediated excitotoxicity contributed to the degeneration of RGCs in glutamate aspartate transporter (GLAST) deficient (KO)

\section{Biomed Central}


mice, the first animal model of normal tension glaucoma [14]. Furthermore, we recently reported that GluN2D deficiency partially protected against the loss of RGCs in GLAST KO mice [15]. These results suggest that other GluN2 subunits, in addition to GluN2D, may contribute to excitotoxic retinal cell death. To address this hypothesis, we examined the roles of the four different GluN2 subtypes in NMDA-induced retinal cell death using mice lacking specific GluN2 subunits. We also evaluated the neuroprotective effect of 7-hydroxy-6-methoxy-2-methyl1-(2-(4-(trifluoromethyl)phenyl)ethyl)-1,2,3,4-tetrahydroisoquinoline hydrochloride (HON0001) [16], an specific GluN2B antagonist, on RGC degeneration due to glutamate excitotoxicity in GLAST KO mice.

In the present study, we report that GluN2B and GluN2D deficiency protect against NMDA-induced excitotoxic retinal cell death, but GluN2A and GluN2C deficiency have no protective effects. We also show that pharmacological blockade of GluN2B subunit attenuates RGC loss in GLAST KO mice.

\section{Results}

NMDA receptor subunits present in mouse RGCs

To investigate the expression of NMDAR subunits in RGCs, we used a single-cell reverse transcriptase polymerase chain reaction (RT-PCR) method. After dissociation of the retina into single cells, RGCs can no longer be identified by their morphology. We therefore used dissociated retina from B6.Cg-TgN(Thy1-CFP)23Jrs/J transgenic mice (thy1-CFP mice), which express cyan fluorescent protein (CFP) in most RGCs [17]. We first confirmed that the CFP-containing cells in the thy1-CFP mouse retina were RGCs by immunostaining with Brn3, a neurochemical marker for RGCs [18]. CFP expression colocalized with Brn3 immunoreactivity in most somata in the ganglion cell layer (GCL) (Figure 1A-C). A single CFP-expressing cell was picked with a glass capillary from the dissociation mix and transferred to the reaction tube (Figure 1D, E), and was further identified as RGC by expression of Brn3 (Figure 1F). Typical results of singlecell RT-PCR on isolated RGCs are shown in Figure 1F. GluN1 and GluN2A-D could be amplified together with an internal control ( $\beta$-actin) from a single RGC, as well as from whole retina. In our samples of 4 isolated RGCs, two cells express GluN1/GluN2A/GluN2B/GluN2C/GluN2D, whereas the other two cells express GluN1/GluN2A/ GluN2B/GluN2D. These results indicate the presence of GluN1 and all GluN2 subunits (GluN2A-D) in the mouse RGCs.

\section{Retinal structure in mice lacking GluN2 subunits}

We used mice lacking any one of the four GluN2 subunits to determine the distinct roles of these GluN2 subunits in NMDA-induced RGC death. Mice lacking GluN2A,
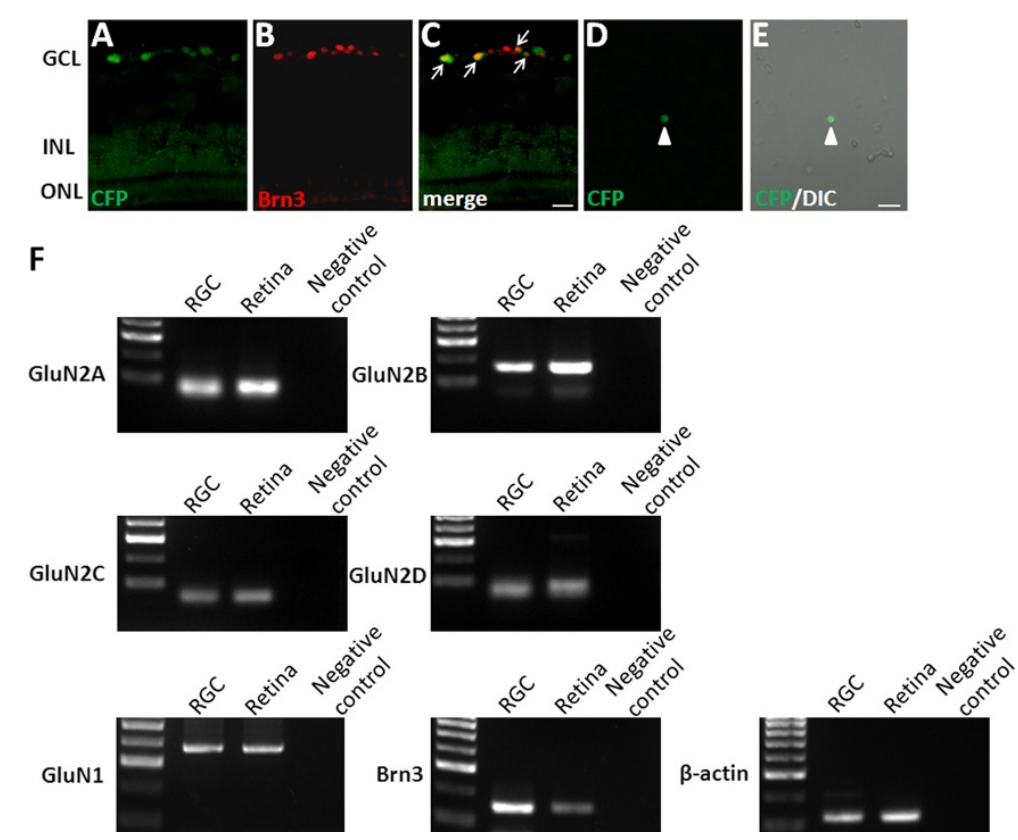

Figure 1 Expression of NMDA receptor subunits in mouse retinal ganglion cell. (A-C) Immunohistochemical analysis of Brn3 (B red) in Thy1-CFP mice. CFP fluorescence (A green) was overlaid with Brn3 (C). Arrows in (C) indicate double-labeled cells. Scale bar, 20 m. (D-E) After dissociation the fluorescent RGC was picked up from the cell suspension. CFP (green) and DIC pictures for the same isolated cell are superimposed (E). Arrowhead indicates CFP-expressing RGC. Scale bar, $20 \mu \mathrm{m}$. (F) Single-cell RT-PCR analysis for GluN1, four GluN2 subunits, Brn3 and $\beta$-actin. Distilled water was used for PCR negative control. GCL, ganglion cell layer; INL, inner nuclear layer; ONL, outer nuclear layer; RGC, retinal ganglion cell. 
GluN2C, and GluN2D are viable [19-21], whereas GluN2Bdeficient mice die shortly after birth [22]. We therefore generated conditional GluN2B KO mice, in which GluN2B was ablated in retinal neurons containing RGCs. For this purpose, we crossed GluN2B ${ }^{\mathrm{f} / \mathrm{f}}$ [23] mice with ckit-Cre mice [24] (GluN2B/f/c-kit-Cre). In c-kit-Cre mice crossed with ROSA-tdTomato reporter mice [25] (ROSAtdTomato/c-kit-Cre), tdTomato-expressing cells were localized in the GCL and inner nuclear layer (INL) and most calretinin immunoreactive cells (RGCs and amacrine cells) contained tdTomato, suggesting that Cre recombinase is expressed in RGCs and cells in the INL, including amacrine cells, in c-kit-Cre mice (Figure 2A). Immunohistochemical analysis revealed that GluN2B protein expression was eliminated in RGCs and cells in the INL in GluN2 $\mathrm{B}^{\mathrm{f} / \mathrm{f}}$ / c-kit-Cre mice (Figure 2B). Western blot analysis showed that GluN2A, GluN2C, and GluN2D proteins were completely eliminated from mutant mice lacking GluN2A, GluN2C, and GluN2D, respectively (Figure 2C, E, F). In GluN2B ${ }^{\mathrm{f} / \mathrm{f}} / \mathrm{c}$-kit-Cre mice, GluN2B expression level in the retina was significantly lower than in control mice (Figure 2D).

We next investigated whether the absence of GluN2 subunits affects the anatomical organization of the retina by histological analyses. Hematoxylin and eosin staining revealed the retinae of GluN2A, GluN2B $/ \mathrm{f} / \mathrm{c}$-kit-Cre, GluN2C, and GluN2D mutant mice to be normally organized, consisting of several different cell layers (Figure 3A). The thickness of the inner retinal layer (IRL) in all mutant strains was normal compared with wild-type (WT) mice (Figure 3B). As previous studies showed that ablation of GluN1 increased cell death in the developing somatosensory thalamus [26], we counted cell numbers in the GCL. The cell number in the GCL of GluN2 $\mathrm{B}^{\mathrm{f} / \mathrm{f}} / \mathrm{c}$-kit-Cre mice was significantly lower than that of WT mice at 5 weeks, whereas cell number in the GCL of the other mutant strains was comparable to that of control mice at 5 weeks (Figure 3C). These results suggest that GluN2B subunit plays a survival role for RGCs during retinal development, but the other GluN2 subunits (GluN2A, GluN2C and GluN2D) are not involved in retinal development and survival in RGCs.

\section{GluN2B and GluN2D deficiency prevents NMDA-induced- excitotoxic retinal cell death}

To determine which GluN2 subtypes are involved in NMDA-induced RGC death in the retina, we examined the effect of intraocular injection of NMDA on retinal cell death in GluN2 KO and WT mice. First, to examine the acute injury of NMDA, TUNEL analysis was performed

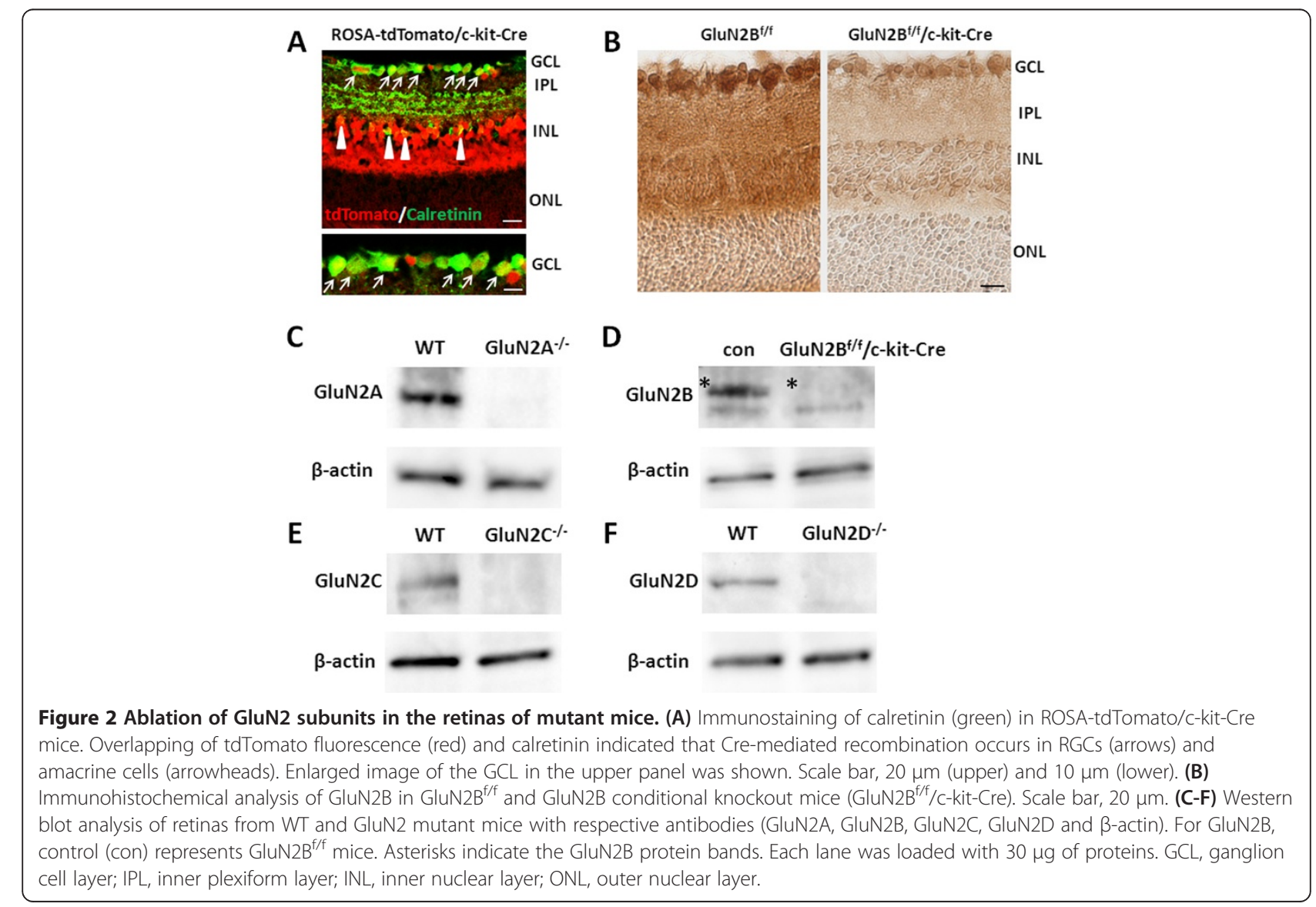




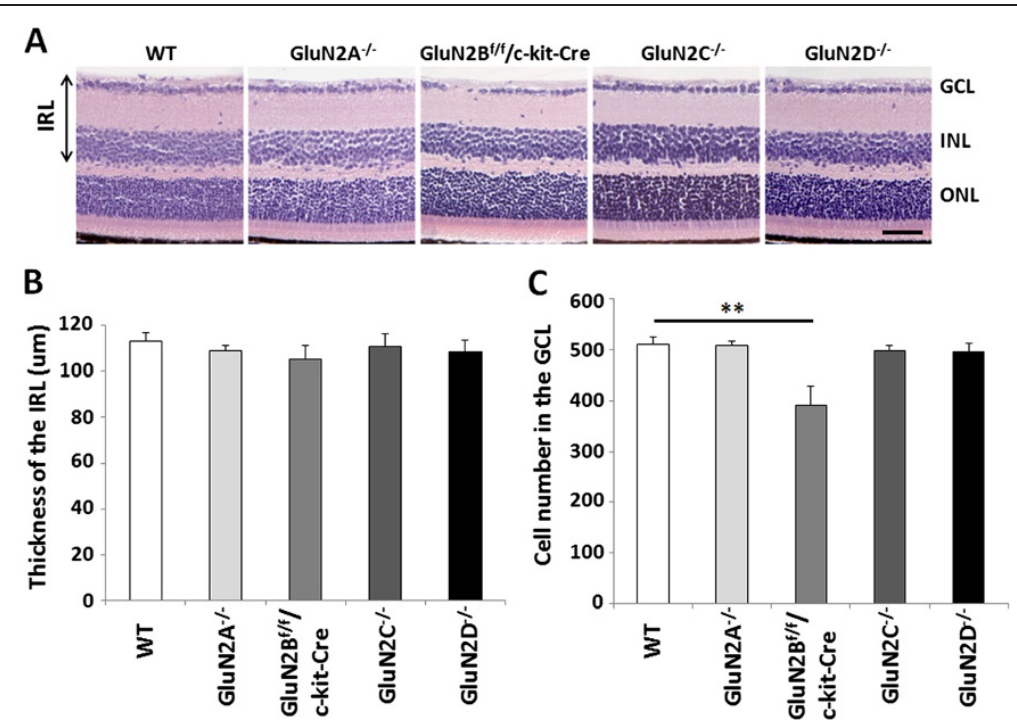

Figure 3 Effects of GluN2 subunits ablation on the morphology of the retina. (A) Hematoxylin and eosin staining (H\&E) of retinal sections at P35 in WT and GluN2 mutant mice. Scale bar, $50 \mu \mathrm{m}$. (B-C) Quantification of thickness of the inner retinal layer (B) and the cell number in the GCL (C) in WT and GluN2 mutant mice. The data are presented as mean \pm S.E.M. of 5 samples for each experiment. ${ }^{* *} P<0.01$. GCL, ganglion cell layer; INL, inner nuclear layer; ONL, outer nuclear layer; IRL, inner retinal layer.

on the retinas of WT and GluN2 mutants at 1 day after NMDA treatment. A number of TUNEL-positive cells were observed in the GCL and INL in both WT and GluN2 mutant strains after NMDA injection (Figure 4A), but the percentage of TUNEL-positive cells in the GCL of GluN2B $\mathrm{B}^{\mathrm{f} / \mathrm{f}} / \mathrm{c}$-kit-Cre and GluN2D ${ }^{-/-}$mice was significantly lower than that in WT mice (Figure 4B). Following NMDA injection, the number of RGCs and the thickness of IRL decreased from days 1 to 7 , with no further decrease being observed from days 7 to 14 [27,28]. To examine the chronic injury of NMDA, morphological changes were measured 7 days after NMDA or phosphate-buffered saline (PBS) injection. Intraocular administration of NMDA induced cell death in the GCL in both WT and GluN2 mutant mice (Figure 4C), but the percentage of surviving cells in the GCL was significantly larger in GluN2B $\mathrm{B}^{\mathrm{f} / \mathrm{f}} / \mathrm{c}-\mathrm{kit}-\mathrm{Cre}$ and GluN2D $\mathrm{D}^{-/-}$mice than in WT mice (Figure 4D). Additionally, the thickness of IRL was significantly larger in GluN2B $\mathrm{f} / \mathrm{f} / \mathrm{c}$-kit-Cre mice than in WT mice (Figure 4E). Taken together, these results suggest that GluN2B and GluN2D were involved in NMDA-induced RGC death.

\section{A specific GluN2B antagonist, HON0001, prevents RGC death in GLAST-deficient mice}

We have reported that the neuroprotective role of apolipoprotein E-containing lipoproteins in glaucomatous retinal degeneration in GLAST KO mice is mediated through promoting interaction between low density lipoprotein receptor-related protein 1 (LRP-1) and the GluN2B subunit [29]. Recently, we have also demonstrated that Dock3 overexpression prevented retinal cell death in GLAST KO mice by promoting GluN2B degradation [28]. To determine whether GluN2B is involved in RGC degeneration in GLAST-deficient mice, we evaluated the effect of a specific GluN2B antagonist, HON0001, on RGC degeneration in GLAST KO mice. As shown in Figure 5, the number of cells in GLAST KO mice subjected to HON0001 $(10 \mathrm{mg} / \mathrm{kg})$ treatment $(281 \pm 26)$ was significantly greater than that in GLAST KO mice not subjected to HON0001 treatment $(203 \pm 10)$. These results suggest that GluN2B is involved in RGC loss in GLAST KO mice.

\section{Discussion}

We previously reported that GluN2D deficiency prevented loss of RGCs in GLAST KO mice [15]. These results suggest that both GluN2B and GluN2D subunits play a critical role in RGC degeneration by glutamate excitotoxicity. Therefore, an GluN2B-selective antagonist in combination with an GluN2D-selective antagonist represents an effective strategy for the management of glaucoma and various forms of retinopathy. We recently showed that Dock3 overexpression prevented excitotoxic RGC death by suppressing the surface expression of GluN2D and enhancing NMDA-mediated GluN2B degradation $[15,28]$. Thus, the design of compounds capable of increasing the expression of Dock3 represents a novel strategy for the treatment of various forms of retinopathy. Previous studies also showed that calcium influx through NMDARs is modulated by LRP-1 [30,31]. These 


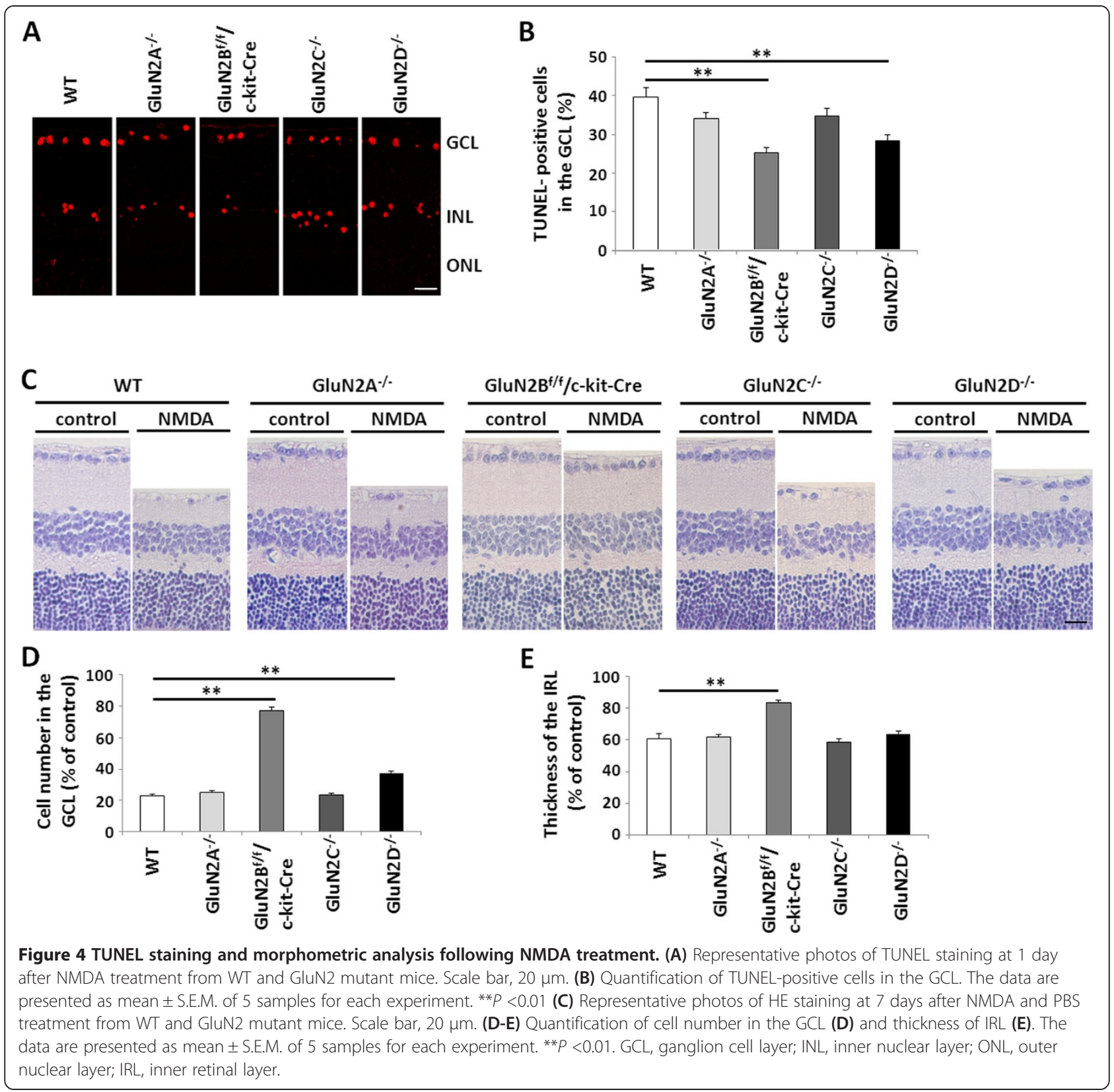

findings may provide a novel therapeutic strategy for various forms of retinopathy that are mediated by Econtaining lipoproteins through LRP-1.

The failure of GluN2C deficiency to protect RGCs from NMDA-induced excitotoxicity can be explained by the data showing that only a small number of RGCs expressed GluN2C [32]. However, almost RGCs express GluN2A [32]. The failure of GluN2A deficiency to protect RGCs from NMDA-induced excitotoxicity may be explained by the distinct functional properties conferred by GluN2 subunits on the receptors, and the different signaling pathway couplings $[13,33]$. This variety is due to the large and divergent cytoplasmic C-terminal domains of GluN2 subunits [34]. A previous report showed that C-terminal domains of GluN2B subunits were more lethal than GluN2A subunits, and different coupling to PSD-95/nNOS signaling cassette may contribute to differential susceptibility of GluN2 subunits to excitotoxic injury [33]. Another possible explanation is that the location of NMDARs at synaptic or extrasynaptic sites determines the neuroprotective or neurotoxic effects of glutamate. A high level of synaptic NMDAR activity promotes neuronal survival, whereas extrasynaptic NMDAR activity promotes cell death [35]. In the retina, GluN2B is 

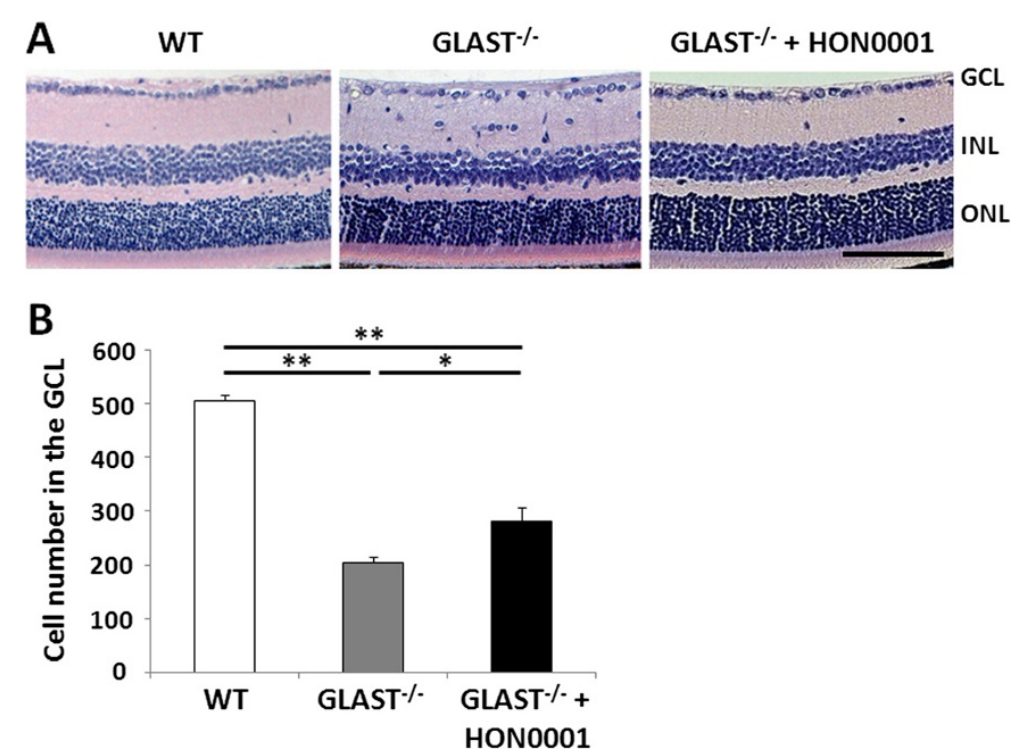

Figure 5 GluN2B antagonist HON0001 rescues RGCs death in GLAST-deficient mice. (A) Representative photos of wild-type (WT), saline-

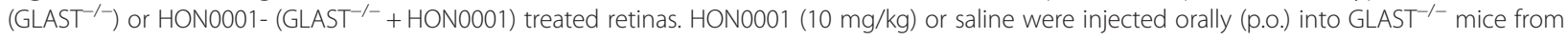
P21 to P35. The animals were killed at P35 after HON0001/saline treatment. Scale bar, $100 \mu \mathrm{m}$. (B) Quantification of the cell number in the GCL. The data are presented as mean \pm S.E.M. of $4\left(\mathrm{WT}\right.$ and $\left.\mathrm{GLAST}^{-/-}\right)$and $6\left(\mathrm{GLAST}^{-/-}+\right.$HON0001) samples for each experiment. ${ }^{*} P<0.05,{ }^{* *} P<0.01$. $\mathrm{GCL}$, ganglion cell layer; INL, inner nuclear layer; ONL, outer nuclear layer.

enriched at the perisynaptic site, whereas synaptic NMDARs primarily contain GluN2A [36].

The number of cells in the GCL of GluN2B $1 / \mathrm{f} / \mathrm{c}$-kitCre mice was significantly decreased at 5 weeks. This finding is consistent with a previous study showing that NMDAR hypofunction increased neuronal death in the developing brain $[26,37]$. GluN2B is a major GluN2 subunit in the immature retina [38]; therefore, ablation of GluN2B in the developing retina can cause excessive neuronal apoptosis, resulting in a reduction in the cell number in the GCL of GluN2B $/ \mathrm{f} / \mathrm{f}$-kit-Cre mice. Thus, loss of GluN2B can increase RGC death in the immature retina, but protect RGCs from glutamate excitotoxicity in the adult.

\section{Conclusions}

We showed that GluN2B- and GluN2D-containing NMDARs played a critical role in NMDA-induced excitotoxic retinal cell death and RGC degeneration in GLAST KO mice. Inhibition of GluN2B and GluN2D activity is a potential therapeutic strategy for the treatment of several retinal diseases, including retinal ischemia, diabetic retinopathy, and glaucoma.

\section{Methods}

\section{Animals}

B6.Cg-TgN(Thy1-CFP)23Jrs/J transgenic mice (thy1-CFP mice) and c-kit-Cre transgenic mice have been described previously $[17,24]$. c-kit-Cre transgenic mice were bred with ROSA-tdTomato mice [25] to examine Cre activity.
c-kit-Cre mice were bred with GluN2B $\mathrm{B}^{\text {flox/lox }}\left(G l u N 2 B^{f / f}\right)$ mice [23] to generate GluN2B conditional knockout mice (GluN2Bfff/c-kit-Cre). The homozygous GluN2A KO (GluN2A $\left.{ }^{-/-}\right)$[19], GluN2C KO mice $\left(G l u N 2 C^{-1-}\right)$ [20] and GluN2D KO mice $\left(G l u N 2 D^{-/-}\right)$[21] were obtained by crossing heterozygous GluN2A ${ }^{+/-}$, GluN2C ${ }^{+/-}$ and GluN2D ${ }^{+/-}$mice, respectively. GLAST KO mice have been described previously $[39,40]$. In all experiments, age matched WT and GluN2B ${ }^{\mathrm{f} / \mathrm{f}}$ littermate controls were used. All mice were of the C57BL/6 J genetic background, and all animal procedures were approved by the Animal Committee of Tokyo Medical and Dental University (0130166C).

\section{Isolation of single ganglion cells from mouse retina and RT-PCR}

5 week old Thy1-CFP mice were deeply anesthetized by diethyl ether and retinas were dissociated by using the Papain Dissociation System (Worthington Biochemical Corporation) at $37^{\circ} \mathrm{C}$ for $30 \mathrm{~min}$. Single-CFP-expressing cell was aspirated by glass microcapillaries and placed into the PCR-tube containing $10 \mu \mathrm{l}$ of resuspention buffer. Single-cell RT-PCR was performed using the SuperScript III CellsDirect cDNA Synthesis System (Invitrogen). Total RNA (5 $\mu \mathrm{g})$ from whole retina were used to synthesize first-strand cDNA by using SuperScript III First-Strand Synthesis System (Invitrogen). The retina cDNA served as positive controls. The following primers were used for cDNA detection: GluN2A FWD: 5' GTG TGC GAC CTC ATG TCC G 3'; REV: 5' GCC TCT TGG TCC GTA TCA TCT C 3'; GluN2B FWD: 5' 
CAG CAA AGC TCG TTC CCA AAA 3'; REV: 5' GTC AGT CTC GTT CAT GGC TAC 3'; GluN2C FWD: ATC CCC GAC GGC TGA GA 3'; REV: 5' TTC CTA GTC CAA GCA CAA AAC G 3'; GluN2D FWD: 5' TGT GTG GGT GAT GAT GTT CGT 3'; REV: 5' CCA CAG GAC TGA GGT ACT CAA AGA 3'; GluN1 FWD: 5' GCC GAT TTA AGG TGA ACA GC 3'; REV: 5' AAT TGT GCT TCT CCA TGT GC 3'; Brn3 FWD: 5' GCA GTC TCC ACT TGG TGC TTA CTC 3'; REV: $5^{\prime}$ TTC CCC CTA CAA ACA AAC CTC C 3'; $\beta$-actin FWD: 5' ATA TCG CTG CGC TGG TCG TC 3'; REV: 5' TCA CTT ACC TGG TGC CTA GGG 3'. The thermal cycler conditions were $5 \mathrm{~min}$ at $94^{\circ} \mathrm{C}$ and then $40 \mathrm{cy}$ cles of $30 \mathrm{~s}$ at $94^{\circ} \mathrm{C}, 30 \mathrm{~s}$ at $60^{\circ} \mathrm{C}$, and $30 \mathrm{~s}$ at $72^{\circ} \mathrm{C}$, followed by $7 \mathrm{~min}$ at $72^{\circ} \mathrm{C}$.

\section{Western blot analysis}

Retinas were quickly removed and homogenized in $100 \mu \mathrm{l}$ of cold lysis buffer $(50 \mathrm{mM}$ Tris- $\mathrm{HCl}, 1 \%$ Nonidet P-40, $5 \mathrm{mM}$ EDTA, $150 \mathrm{mM} \mathrm{NaCl}, 0.5 \% \mathrm{Na}$-deoxycholate, $1 \mathrm{mM} \mathrm{MgCl}_{2}, 1 \mathrm{mM}$ DTT, $1 \mathrm{mM} \mathrm{Na} \mathrm{VO}_{4}, 1 \mathrm{mM} \mathrm{NaF}$, $1 \mathrm{mM}$ phenylmethylsulfonyl fluoride (PMSF), and Complete Protease Inhibitor Cocktail [Roche]). Protein concentration was determined by BCA Protein Assay kit (Sigma-Aldrich). Thirty microgram of the protein was loaded per lane. Primary antibodies used were GluN2A (1:500, Covance), GluN2B (1:500) [41], GluN2C (1:100, Invitrogen), GluN2D (1:500) [42], $\beta$-actin (1:1000, Santa Cruz). They were then incubated with anti-rabbit, guinea pig or mouse IgG-HRP-conjugated secondary antibody (1:5000, Jackson ImmunoResearch). SuperSignal West Femto Maximum Sensitivity Substrate (Thermo Scientific) was used to visualize the immunoreactive proteins.

\section{Immunohistochemistry}

Sections were prepared as previously described [15]. Frozen retinal sections of $12 \mu \mathrm{m}$ thickness were incubated using anti-Brn3 (1:50, Santa Cruz), anti-calretinin (1:500, Swant) and anti-GluN2B (1:100) antibodies. For Brn3 and calretinin detection, Cy-3-conjugated donkey antigoat IgG (1:500, Jackson ImmunoResearch) and goat anti-rabbit IgG Alexa 488 (1:1000, Molecular Probes) were used as secondary antibodies. For GluN2B detection, peroxidase labelled polymer conjugated to goat anti-rabbit IgG (DAKO) was used as secondary antibody. Images were recorded with an LSM-510 META confocal laser microscope (Carl Zeiss).

\section{Histology and morphometric analysis}

Eyes from mice at postnatal day 35 (P35) were enucleated and fixed in Davidson's solution fixative [43], then embedded in paraffin wax. In some experiments, HON0001 (10 mg/kg, a gift from T. Honda at Hoshi University) [16] or saline was injected orally (p.o.) into GLAST KO mice daily from P21 to P35. These mice were sacrificed on P35 and processed for RGC count. Paraffin sections $(7 \mu \mathrm{m}$ thick) were cut though the optic nerve and stained with hematoxylin and eosin (H\&E). The number of neurons in the GCL was counted as previously described [15]. The thickness of the IRL (from GCL to INL) was measured at a distance of 0.5 to $1.0 \mathrm{~mm}$ from optic disc.

\section{Animal models of NMDA-induecd retinal neuronal death and morphometric analysis}

Intravitreal injection of NMDA (Sigma) was conducted as previously described [15]. Briefly, a single 2- $\mu$ l injection of $20 \mathrm{mM}$ NMDA in $0.1 \mathrm{M}$ PBS ( $\mathrm{pH} 7.4$ ) was administered intravitreally into the right eye of each mouse, the same volume of PBS was administered to the contralateral (left) eye as control. The animals were sacrificed at 1 day or 7 days after injection, and eyes were enucleated for morphometric and TUNEL analysis. Paraffin sections ( $5 \mu \mathrm{m}$ thick) were cut though the optic nerve and stained with $\mathrm{H} \& \mathrm{E}$. The extent of NMDAinduced retinal cell death after 7 days was quantified by counts of neurons in the GCL and the thickness of the IRL. The changes of the number of ganglion cells and thickness of IRL after NMDA injection were expressed as percentages of the control eyes.

\section{TUNEL staining}

At 1 day after the NMDA or PBS injection, TUNEL staining was performed with paraffin sections (5 $\mu \mathrm{m}$ thick) according to the manufacturer's instructions (Promega). Fluorescence detection was carried out using Alexa-fluor -568-conjugated streptavidin (Molecular Probes). TUNELpositive cells in the GCL were counted and expressed as percentages of total DAPI stained cells in the GCL.

\section{Statistics}

Statistical analyses were conducted using Student's t-test for comparison between two samples, or one-way ANOVA followed by Bonferroni's test for multiple comparisons, using the SPSS 17.0 software package. Data are expressed as mean \pm S.E.M. $P$ values $<0.05$ were considered statistically significant.

\section{Abbreviations \\ GLAST: Glutamate aspartate transporter; INL: Inner nuclear layer; IPL: inner plexiform layer; IRL: Inner retina layer; LRP: lipoprotein receptor-related protein; NMDAR: N-methyl-D-aspartate receptor; PBS: Phosphate-buffered saline; PMSF: Phenylmethylsulfonyl fluoride; RGC: Retinal ganglion cell; RT-PCR: Reverse transcriptase polymerase chain reaction; WT: Wild-type. \\ Competing interests \\ The authors declare that they have no competing interests.}

\section{Authors' contributions}

$K T, N B$, and TA conceived and designed the experiments. NB, SK and MY carried out experiments and analyzed the data. KS and MM contributed reagents and materials. KT and NB wrote the paper. All authors have read and approved the manuscript for publication. 


\section{Acknowledgements}

We thank M. Watanabe and T. Honda for GluN2B and GluN2D antibody and for HON0001, respectively. We also thank Y. Hiraoka for technical support. This study was supported by "Understanding of molecular and environmental bases for brain health" executed under the Strategic Research Program for Brain Sciences from the Ministry of Education, Culture, Sports, Science and Technology, Japan (KT) and by the Ministry of health, Labor and Welfare of Japan (KT).

\section{Author details}

'Laboratory of Molecular Neuroscience, Medical Research Institute, Tokyo Medical and Dental University, 1-5-45 Yushima, Bunkyo-ku, Tokyo 113-8510, Japan. ${ }^{2}$ The Center for Brain Integration Research, Tokyo Medical and Dental University, Tokyo, Japan. ${ }^{3}$ JST, CREST, Saitama, Japan. ${ }^{4}$ College of Basic Medicine, China Medical University, 92 Bei Er Road, Heping District, Shenyang 110001, China. ${ }^{5}$ Department of Cellular Neurobiology, Brain Research Institute, Niigata University, Niigata 951-8585, Japan. ${ }^{6}$ Brain Science Laboratory, The Research Organization of Science and Technology, Ritsumeikan University, Nojihigashi 1-1-1, Kusatsu, Shiga 525-8577, Japan.

Received: 11 July 2013 Accepted: 29 July 2013

Published: 31 July 2013

\section{References}

1. Choi DW: Glutamate neurotoxicity and diseases of the nervous system. Neuron 1988, 1:623-634.

2. Choi DW, Rothman SM: The role of glutamate neurotoxicity in hypoxic-ischemic neuronal death. Annu Rev Neurosci 1990, 13:171-182.

3. Chapman AG: Glutamate and epilepsy. J Nutr 2000, 130(4S Suppl):1043S-1045S.

4. Meldrum B: Amino acids as dietary excitotoxins: a contribution to understanding neurodegenerative disorders. Brain Res Brain Res Rev 1993, 18:293-314

5. Kalia LV, Kalia SK, Salter MW: NMDA receptors in clinical neurology: excitatory times ahead. Lancet Neurol 2008, 7:742-755.

6. Casson RJ: Possible role of excitotoxicity in the pathogenesis of glaucoma. Clin Experiment Ophthalmol 2006, 34:54-63.

7. Kaur C, Foulds WS, Ling EA: Hypoxia-ischemia and retinal ganglion cell damage. Clin Ophthalmol 2008, 2:879-889

8. Hernández C, Simó R: Neuroprotection in diabetic retinopathy. Curr Diab Rep 2012, 12:329-337.

9. Honkanen RA, Baruah S, Zimmerman MB, Khanna CL, Weaver YK, Narkiewicz J, Waziri R, Gehrs KM, Weingeist TA, Boldt HC, et al: Vitreous amino acid concentrations in patients with glaucoma undergoing vitrectomy. Arch Ophthalmol 2003, 121:183-188.

10. Levkovitch-Verbin H, Martin KR, Quigley HA, Baumrind LA, Pease ME, Valenta D: Measurement of amino acid levels in the vitreous humor of rats after chronic intraocular pressure elevation or optic nerve transection. J Glaucoma 2002, 11:396-405.

11. Carter-Dawson L, Crawford ML, Harwerth RS, Smith EL, Feldman R, Shen FF, Mitchell CK, Whitetree A: Vitreal glutamate concentration in monkeys with experimental glaucoma. Invest Ophthalmol Vis Sci 2002, 43:2633-2637.

12. Ferreira IL, Duarte CB, Carvalho AP: Ca2+ influx through glutamate receptor-associated channels in retina cells correlates with neuronal cell death. Eur J Pharmacol 1996, 302:153-162.

13. Cull-Candy S, Brickley S, Farrant M: NMDA receptor subunits: diversity, development and disease. Curr Opin Neurobiol 2001, 11:327-335.

14. Harada T, Harada C, Nakamura K, Quah HM, Okumura A, Namekata K, Saek T, Aihara M, Yoshida H, Mitani A, et al: The potential role of glutamate transporters in the pathogenesis of normal tension glaucoma. J Clin Invest 2007, 117:1763-1770.

15. Bai N, Hayashi H, Aida T, Namekata K, Harada T, Mishina M, Tanaka K: Dock3 interaction with a glutamate-receptor NR2D subunit protects neurons from excitotoxicity. Mol Brain 2013, 6:22.

16. Suetake-Koga S, Shimazaki T, Takamori K, Chaki S, Kanuma K, Sekiguchi Y, Suzuki T, Kikuchi T, Matsui Y, Honda T: In vitro and antinociceptive profile of HON0001, an orally active NMDA receptor NR2B subunit antagonist. Pharmacol Biochem Behav 2006, 84:134-141.

17. Feng G, Mellor RH, Bernstein M, Keller-Peck C, Nguyen QT, Wallace M, Nerbonne JM, Lichtman JW, Sanes JR: Imaging neuronal subsets in transgenic mice expressing multiple spectral variants of GFP. Neuron 2000, 28:41-51.
18. Xiang M, Zhou L, Peng YW, Eddy RL, Shows TB, Nathans J: Brn-3b: a POU domain gene expressed in a subset of retinal ganglion cells. Neuron 1993, 11:689-701.

19. Sakimura K, Kutsuwada T, Ito I, Manabe T, Takayama C, Kushiya E, Yagi T, Aizawa S, Inoue $Y$, Sugiyama H: Reduced hippocampal LTP and spatial learning in mice lacking NMDA receptor epsilon 1 subunit. Nature 1995, 373:151-155.

20. Kadotani H, Hirano T, Masugi M, Nakamura K, Nakao K, Katsuki M, Nakanishi S: Motor discoordination results from combined gene disruption of the NMDA receptor NR2A and NR2C subunits, but not from single disruption of the NR2A or NR2C subunit. J Neurosci 1996, 16:7859-7867.

21. Ikeda K, Araki K, Takayama C, Inoue Y, Yagi T, Aizawa S, Mishina M: Reduced spontaneous activity of mice defective in the epsilon 4 subunit of the NMDA receptor channel. Brain Res Mol Brain Res 1995, 33:61-71.

22. Kutsuwada T, Sakimura K, Manabe T, Takayama C, Katakura N, Kushiya E, Natsume R, Watanabe M, Inoue Y, Yagi T, et al: Impairment of suckling response, trigeminal neuronal pattern formation, and hippocampal LTD in NMDA receptor epsilon 2 subunit mutant mice. Neuron 1996, 16:333-344.

23. Akashi K, Kakizaki T, Kamiya H, Fukaya M, Yamasaki M, Abe M, Natsume R, Watanabe M, Sakimura K: NMDA receptor GluN2B (GluR epsilon 2/NR2B) subunit is crucial for channel function, postsynaptic macromolecular organization, and actin cytoskeleton at hippocampal CA3 synapses. J Neurosci 2009, 29:10869-10882.

24. Eriksson B, Bergqvist I, Eriksson M, Holmberg D: Functional expression of Cre recombinase in sub-regions of mouse CNS and retina. FEBS Lett 2000, 479:106-110.

25. Madisen L, Zwingman TA, Sunkin SM, Oh SW, Zariwala HA, Gu H, Ng LL, Palmiter RD, Hawrylycz MJ, Jones AR, et al: A robust and high-throughput Cre reporting and characterization system for the whole mouse brain. Nat Neurosci 2010, 13:133-140.

26. Adams SM, de Rivero Vaccari JC, Corriveau RA: Pronounced cell death in the absence of NMDA receptors in the developing somatosensory thalamus. J Neurosci 2004, 24:9441-9450.

27. Endo K, Nakamachi T, Seki T, Kagami N, Wada Y, Nakamura K, Kishimoto K, Hori M, Tsuchikawa D, Shinntani N, et al: Neuroprotective effect of PACAP against NMDA-induced retinal damage in the mouse. $J \mathrm{Mol}$ Neurosci 2011, 43:22-29.

28. Namekata K, Kimura A, Kawamura K, Guo X, Harada C, Tanaka K, Harada T: Dock3 attenuates neural cell death due to NMDA neurotoxicity and oxidative stress in a mouse model of normal tension glaucoma. Cell Death Differ 2013. doi:10.1038/cdd.2013.91.

29. Hayashi H, Eguchi Y, Fukuchi-Nakaishi Y, Takeya M, Nakagata N, Tanaka K, Vance JE, Tanihara H: A potential neuroprotective role of apolipoprotein E-containing lipoproteins through low density lipoprotein receptorrelated protein 1 in normal tension glaucoma. J Biol Chem 2012 287:25395-25406

30. Qiu Z, Strickland DK, Hyman BT, Rebeck GW: alpha 2-Macroglobulin exposure reduces calcium responses to $\mathrm{N}$-methyl-D-aspartate via low density lipoprotein receptor-related protein in cultured hippocampal neurons. J Biol Chem 2002, 277:14458-14466.

31. Martin AM, Kuhlmann C, Trossbach S, Jaeger S, Waldron E, Roebroek A, Luhmann HJ, Laatsch A, Weggen S, Lessmann V, et al: The functional role of the second NPXY motif of the LRP1 beta-chain in tissue-type plasminogen activator-mediated activation of $\mathrm{N}$-methyl-D-aspartate receptors. J Biol Chem 2008, 283:12004-12013.

32. Jakobs TC, Ben Y, Masland RH: Expression of mRNA for glutamate receptor subunits distinguishes the major classes of retinal neurons, but is less specific for individual cell types. Mol Vis 2007, 13:933-948.

33. Martel MA, Ryan TJ, Bell KF, Fowler JH, McMahon A, Al-Mubarak B, Komiyama NH, Horsburgh K, Kind PC, Grant SG, et al: The subtype of GluN2 C-terminal domain determines the response to excitotoxic insults. Neuron 2012, 74:543-556.

34. Ryan TJ, Emes RD, Grant SG, Komiyama NH: Evolution of NMDA receptor cytoplasmic interaction domains: implications for organisation of synaptic signalling complexes. BMC Neurosci 2008, 9:6.

35. Hardingham GE, Bading H: Synaptic versus extrasynaptic NMDA receptor signalling: implications for neurodegenerative disorders. Nat Rev Neurosci 2010, 11:682-696.

36. Zhang J, Diamond JS: Subunit- and pathway-specific localization of NMDA receptors and scaffolding proteins at ganglion cell synapses in rat retina. J Neurosci 2009, 29:4274-4286. 
37. Ikonomidou C, Bosch F, Miksa M, Bittigau P, Vöckler J, Dikranian K, Tenkova $\mathrm{Tl}$, Stefovska V, Turski L, Olney JW: Blockade of NMDA receptors and apoptotic neurodegeneration in the developing brain. Science 1999 283:70-74.

38. Watanabe M, Mishina M, Inoue Y: Differential distributions of the NMDA receptor channel subunit mRNAs in the mouse retina. Brain Res 1994, 634:328-332.

39. Harada T, Harada C, Watanabe M, Inoue Y, Sakagawa T, Nakayama N, Sasaki S, Okuyama S, Watase K, Wada K, et al: Functions of the two glutamate transporters GLAST and GLT-1 in the retina. Proc Natl Acad Sci USA 1998, 95:4663-4666

40. Watase K, Hashimoto K, Kano M, Yamada K, Watanabe M, Inoue Y, Okuyama S, Sakagawa T, Ogawa S, Kawashima N, et al: Motor discoordination and increased susceptibility to cerebellar injury in GLAST mutant mice. Eur J Neurosci 1998, 10:976-988.

41. Watanabe M, Fukaya M, Sakimura K, Manabe T, Mishina M, Inoue Y: Selective scarcity of NMDA receptor channel subunits in the stratum lucidum (mossy fibre-recipient layer) of the mouse hippocampal CA3 subfield. Eur J Neurosci 1998, 10:478-487.

42. Wu Y, Kawakami R, Shinohara Y, Fukaya M, Sakimura K, Mishina M, Watanabe M, Ito I, Shigemoto R: Target-cell-specific left-right asymmetry of NMDA receptor content in schaffer collateral synapses in epsilon1/NR2A knock-out mice. J Neurosci 2005, 25:9213-9226.

43. Chi ZL, Akahori M, Obazawa M, Minami M, Noda T, Nakaya N, Tomarev S, Kawase K, Yamamoto T, Noda S, et al: Overexpression of optineurin E50K disrupts Rab8 interaction and leads to a progressive retinal degeneration in mice. Hum Mol Genet 2010, 19:2606-2615.

doi:10.1186/1756-6606-6-34

Cite this article as: Bai et al: NMDA receptor subunits have different roles in NMDA-induced neurotoxicity in the retina. Molecular Brain 2013 6:34.

\section{Submit your next manuscript to BioMed Central and take full advantage of:}

- Convenient online submission

- Thorough peer review

- No space constraints or color figure charges

- Immediate publication on acceptance

- Inclusion in PubMed, CAS, Scopus and Google Scholar

- Research which is freely available for redistribution 